\title{
Limitada producción científica de la comunidad universitaria: Rol del jurado de tesis
}

\author{
Limited scientific production of the university community: Thesis jury role
}

\section{Sr. Editor:}

Al igual que Arpita Rojas (1) compartimos la preocupación acerca de la limitada producción científica por parte de la comunidad universitaria en el Perú; no obstante, quisiéramos llevar la discusión a un contexto que necesariamente debería impulsar la producción científica estudiantil; hablamos de la publicación de tesis de pregrado que en los últimos años ha demostrado ser baja y preocupante $(2,3)$.

Consideramos que, así como los incentivos tienen un rol motivador para la publicación científica, existe también un rol poco estudiado en el ámbito peruano, en este caso, nos referimos a quienes son nombrados como responsables para asesorar y evaluar los trabajos de grado; especialmente orientaremos nuestro argumento hacia los jurados de tesis que en algunas universidades son conocidos como dictaminadores; en cuanto al rol del asesor, se caracteriza por saber escuchar y atender, ser competente, mantener buen ánimo, tener una metodología clara y precisa, y sobre todo mostrar compromiso con la formación de investigador (4).

El jurado de tesis o comité dictaminador viene a ser un selecto grupo de expertos profesionales en determinada especialidad, quienes tienen la responsabilidad de evaluar tanto el proyecto de investigación como el informe final de tesis (5). En la mayoría de las universidades en el Perú, tanto privadas como estatales, esta labor generalmente se lleva a cabo en dos etapas: la primera en cuanto el tesista presenta su proyecto de investigación y la segunda cuando presenta el informe final de investigación o tesis. No obstante, es precisamente esta labor la que demuestra algunas deficiencias en la medida que el jurado dictaminador carece de experticia en metodología de la investigación científica y sobre todo en producción científica. Respecto a esto último, un estudio realizado por Mamani, Ventura y Caycho (6), hallaron que solo 23 jurados de una población de 131, pertenecientes a una facultad de salud de una universidad privada peruana, había publicado alguna vez en su vida, y solo 9 lograron hacerlo en revistas indizadas en Scopus.

Aunque en el Perú el tema de la producción científica de quienes evalúan las tesis de grado, ha sido poco estudiado, es de suponer que quien no tenga experiencia o ejercicio vigente en publicación científica no pueda orientar adecuadamente el desarrollo de una tesis. Pues la labor del comité dictaminador no solamente es criticar o indicar los cambios a realizar, más bien, este tiene la función de emitir juicios y observaciones en pos de la mejora de la calidad metodológica del trabajo, lo cual debe orientar a la obtención de conocimiento científico. En cambio, muchos jurados limitan su labor a solo evaluar el formato y estilo de redacción de la tesis, dejando de lado aspectos importantes como la calidad de los resultados, el potencial publicable de los hallazgos, lo cual, los lleva a centrar su labor en solo acompañar en el proceso hasta el día de la sustentación.

En conclusión, la producción científica desde el pregrado estaría afectada en función de la falta

Universidad Peruana Unión. Juliaca, Perú

a Docente investigador. Magister en Educación 
de experiencia en publicación científica de quienes asumen la responsabilidad de ser jurado dictaminador de tesis, limitando las etapas de la investigación a solo la difusión en el acto de la sustentación, mas no, en la publicación de los resultados en una revista indexada de especialidad, que es donde se valoran adecuadamente los hallazgos por la comunidad científica.

\section{Oscar J. Mamani-Benito ${ }^{1, a}$}

\section{Correspondencia:}

Oscar Javier Mamani-Benito

Avenida Simón Bolivar \#1019, Puno

Teléfono: 51959925651.

ORCID: https://orcid.org/0000-0002-9818-2601

Correo electrónico: oscar.mb@upeu.edu.pe

\section{REFERENCIAS BIBLIOGRÁFICAS}

1. Arpita AM. Limitada producción científica de la comunidad universitaria: Rol de los incentivos. Rev Méd Hered. 2019; 30(3): 211-212. DOI: https://doi. org/10.20453/rmh.v30i3.3595

2. Atamari N, Roque JS, Robles RA, Nina PI, Falcon BM. Publicación de tesis de pregrado en una facultad de Medicina en Cusco, Perú. Rev Méd Hered. 2015; 26(4):217-221. DOI: https://doi.org/10.20453/rmh. v26i4.2707
3. Mamani OJ. Calidad metodológica y características de las tesis de pregrado de psicología de una universidad privada del Perú. Propósitos y Representaciones. 2018; 6(2)301-338. DOI: http://dx.doi.org/10.20511/ pyr2018.v6n2.224

4. Mamani OJ. La asesoría de tesis en pregrado: una labor que requiere un nuevo enfoque. Rev Med Hered. 2019; 30(2): 124-125. DOI: $10.20453 / \mathrm{rmh}$. v30i 2.3555

5. Alejo MC. Caracterización del Jurado Evaluador de Trabajos de Grado, Maestría y Tesis Doctorales. Una Aproximación. 2017; 17(1,2):10-30. (Citado el 20 de diciembre de 2019). Disponible en: http://revistas. upel.edu.ve/index.php/sinopsis_educativa/article/ view/6718

6. Mamani OJ, Ventura J, Caycho T. Publicación científica de docentes que conforman el jurado dictaminador de tesis en una Facultad de Ciencias de la Salud peruana. Revista Cubana de Información en Ciencias de la Salud. 2019; 30(3):e1373. (Citado el 20 de diciembre de 2019). Disponible en http:// scielo.sld.cu/pdf/ics/v30n3/2307-2113-ics-3003-e1373.pdf

Recibido: 21/01/2020 